\title{
Efeito do Envelhecimento no Albedo de Pavimentos de Concreto Pigmentado'
}

\section{Ageing Effect in Coloured Concrete Pavements Albedo}

\author{
Kowalski, Luiz Fernando'; Masiero, Érico²; Fernandes, Maria Eugênia³ \\ 1 Universidade Federal de São Carlos, Rod. Washington Luiz, s/n, São Carlos - \\ SP, 13565-905, Brasil, fernando.kowalski@unasp.edu.br \\ 2 Universidade Federal de São Carlos, ericomasiero@yahoo.com.br \\ 3 Universidade Federal de São Carlos, fernandes.me88@gmail.com
}

\begin{abstract}
RESUMO
Os pavimentos frios são considerados instrumentos estratégicos no controle do microclima das cidades. Por isso, é necessário o entendimento das propriedades termo físicas desses materiais e formas de potencializar os mecanismos de resfriamento. Neste contexto, a alteração do albedo da superfície pavimentada através da pigmentação é uma das alternativas. Entretanto, a refletância solar ou o albedo dos pavimentos tendem a sofrer alterações com a idade ou tempo de utilização. Sendo assim, este artigo tem por objetivo analisar o efeito do envelhecimento no albedo de pavimentos coloridos. Para isso, foram mensurados in loco a refletância de três colorações de pavimentos intertravados de concreto, utilizando o espectrômetro portátil Alta ll e as recomendações normativas da ASTM C1549-16. O ensaio foi realizado em amostras no estado novo e envelhecido pela intempérie e abrasão. Os resultados parciais da pesquisa apresentaram uma diminuição na refletância dos materiais com cores mais claras e um aumento nos pavimentos mais escuros, com o passar do tempo. Esses valores também foram comparados às estimativas de envelhecimento através de correlações matemáticas, que apresentaram uma variação inferior a 1,28\%, que demonstram que a avaliação por equacionamento é uma proposta válida na predição do albedo do pavimento envelhecido.
\end{abstract}

Palavras-chave: albedo, envelhecimento de pavimentos externos, pavimentos de concreto.

\begin{abstract}
Cool pavements are considered strategic instruments in the microclimate control of the cities. Therefore, it is necessary to understand the thermal properties of this material and ways to potentiate the cooling mechanisms. In this context, the changing of the albedo of the paved surface through pigmentation is one of the alternatives. However, the solar reflectance or albedo of this type of pavement tends to changes, caused by age or time of use. Therefore, this article aims to analyze the effect of ageing on the albedo of colored pavements. For this, the reflectance of three interlocking concrete pavements was measured, using the Alta II portable spectrometer and the normative recommendations of ASTM C1549-16. The assay was
\end{abstract}

${ }^{1}$ KOWALSKI, L.F.; FERNANDES, M.E.; MASIERO, E. Efeito do envelhecimento no albedo de pavimentos de concreto pigmentado. In: SIMPÓSIO NACIONAL DE GESTÃO E ENGENHARIA URBANA, 2., 2019, São Paulo. Anais... São Paulo: USP, 2019. 
performed on fresh and aged samples. The results showed a decrease in the reflectance of the light materials and an increase in the darker pavements, as time went by. These values were also compared to estimates of ageing through mathematical correlations, which presented a variation lower than $1.28 \%$, which demonstrate that the equation is a valid proposal in the prediction of pavement albedo aged.

Keywords: albedo, external pavement ageing, concrete pavement.

\section{INTRODUÇÃO}

A alteração no microclima impacta diretamente nas condições de conforto urbano e no desempenho térmico das edificações. Por isso, as ilhas de calor urbanas (ICU) são uma das mais importantes manifestações da climatologia das cidades (ERELL, PEARMUTTER, WILLIAMSON, 2011).

Assim, a busca tem sido em torno da elaboração de estratégias de mitigação desse problema urbano. O pavimento nesse contexto tem sido um agravante deste problema. Entretanto, ele pode definitivamente ser parte da solução, desde que tenha materiais e projeto adequado (LI, 2016). Com o uso de pavimentos frios, o problema de ICU seria potencialmente mitigado em determinados casos, bem como a durabilidade das vias urbanas.

Segundo Santamouris e Kolokotsa (2016), pavimentos frios são materiais desenvolvidos para apresentar baixas temperaturas de superfície e mitigar as ICU. Segundo Li (2016), o entendimento dos mecanismos de resfriamento e o estudo das propriedades térmicas dos pavimentos frios são fatores importantes no estudo de mitigação das ICU. O aumento da taxa evaporativa e da convecção entre pavimento e ar são alguns exemplos desse mecanismo para a diminuição da temperatura superficial.

Ferreira e Prado (2003) mencionam que o albedo da superfície é o termo aplicado à refletância total de determinado sistema, considerando a razão entre o fluxo refletido e incidente, ambos integrados sobre o espectro solar. Além disso, a natureza destas radiações é térmica. O espectro da radiação está dividido em três diferentes regiões: Ultravioleta, Visível e Infravermelho, que são formadas por ondas curtas.

Além disso, a modificação das propriedades térmicas do material do pavimento tem um importante papel, como o aumento da condutividade, emissividade, da capacidade térmica e da refletância superficial das vias pavimentadas. Entretanto, o albedo dos pavimentos de concreto tende a sofrer alterações com o tempo de utilização (FERREIRA e PRADO, 2003).

Assim esta pesquisa se justifica, pois a redução do albedo da superfície pavimentada é uma das estratégias de mitigação de ilhas de calor urbana, e a alteração do pigmento das vias urbanas poderia causar uma redução desse fenômeno. Sendo assim, este artigo tem por objetivo analisar o efeito do envelhecimento no albedo de pavimentos coloridos intertravados de concreto.

\section{MATERIAIS E MÉTODOS}

O método da pesquisa se estrutura em cinco etapas principais:

- Caracterização do local de estudo;

- Medição da refletância de pavimentos novos e envelhecidos pela intempérie e abrasão, nas cores vermelho, grafite e cinza através do espectrômetro portátil Alta ll;

- Estimativa do albedo no estado envelhecido através de equacionamento;

- Análise da variação do albedo entre o estado novo e envelhecido;

- Análise da variação entre o albedo mensurado pelo espectrômetro portátil e o albedo estimado pelo equacionamento matemático.

Na Figura 1 está apresentado o fluxograma da pesquisa. 
Figura 1 - Fluxograma da pesquisa.

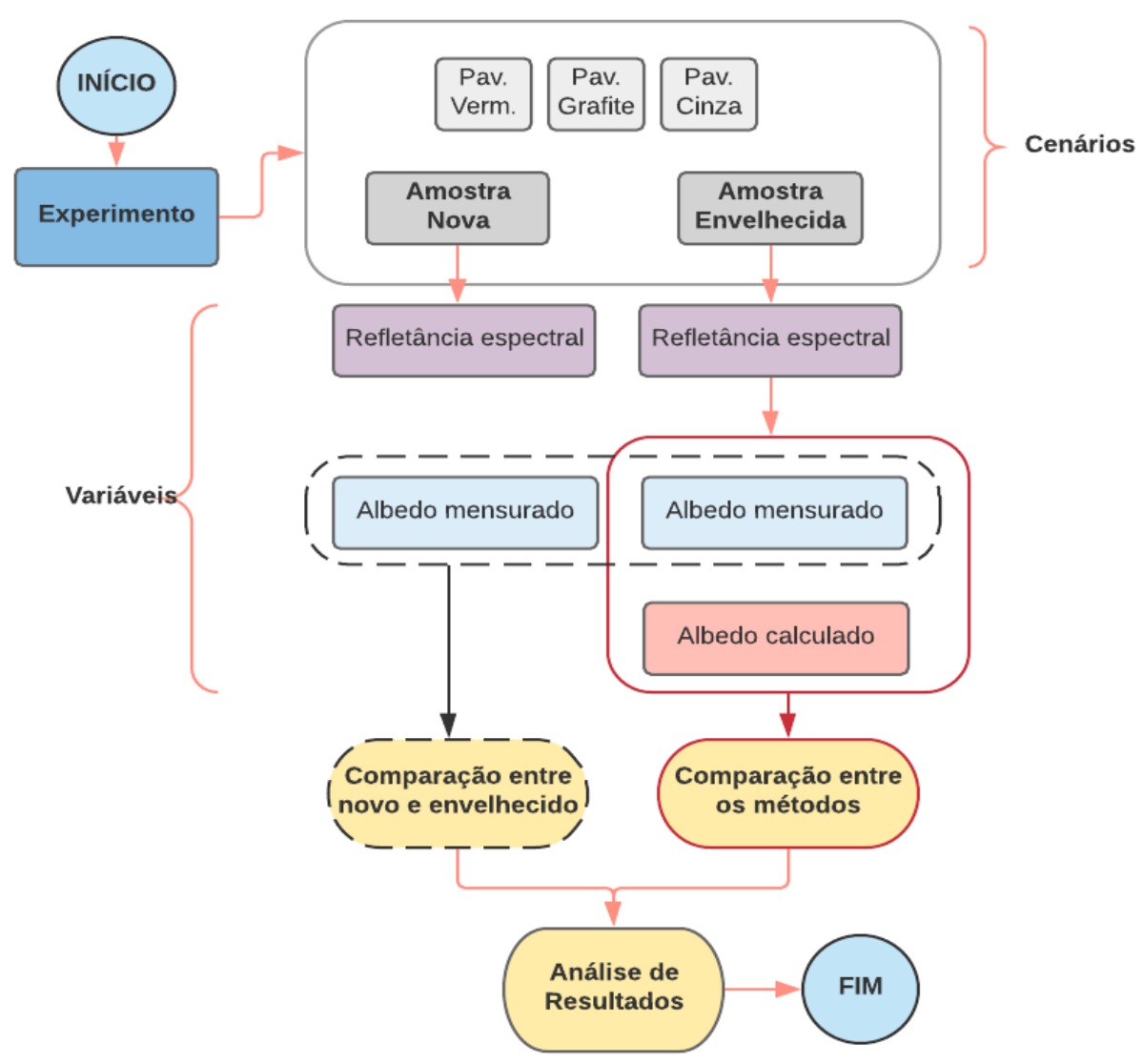

Fonte: Os Autores (2019)

\subsection{Caracterização do local}

O local de estudo para análise do pavimento de concreto novo, foi o campo de experimentos em térmica do campus do Centro Universitário Adventista de São Paulo - UNASP, localizado na cidade de Engenheiro Coelho - SP. Para análise do estado envelhecido, foi adotado um pavimento intertravado de concreto colorido, construído há aproximadamente dois anos, exposto a partículas de poeira de área rural, com predominância de circulação de pedestres e máquinas, conforme apresentado na Figura 2. O método foi aplicado para a obtenção da refletância solar e espectral das amostras de três colorações de pavimento, com amostras no estado novo e envelhecido. O experimento foi realizado no mesmo dia para ambos os cenários.

Figura 2 - Pavimento novo e envelhecido respectivamente.
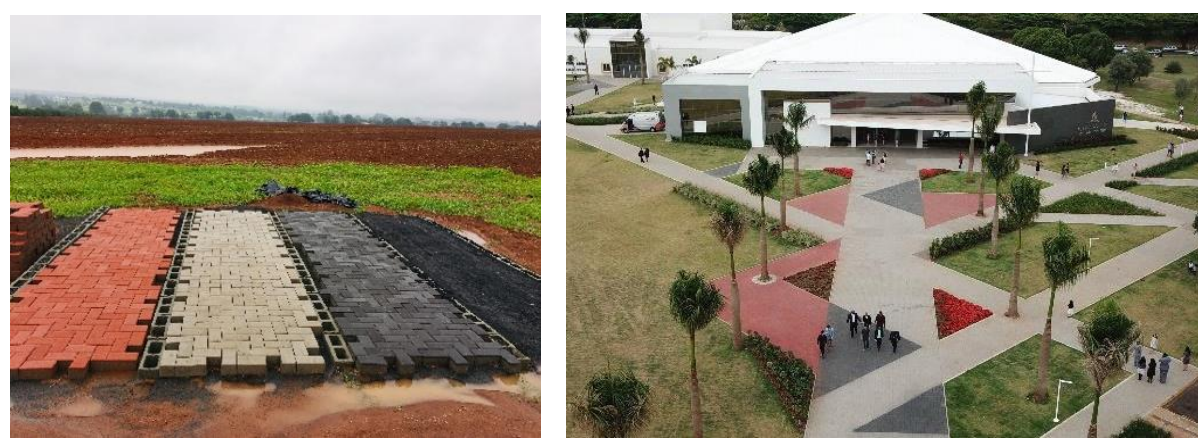

Fonte: Os Autores (2019) 


\subsection{Cálculo da refletância através do espectrômetro portátil}

Para a realização deste estudo, foi empregado o espectrômetro portátil Alta II, conforme apresentado no Quadro 1, e seguindo as recomendações normativas da ASTM C1549-16.

Quadro 1 - Especificações técnicas.

\begin{tabular}{|l|l|l|}
\hline & Marca & Lunar and Planetary Institute / ALTA II \\
\hline Aquisição de dados & 11 comprimentos de onda $(\lambda=470-940 \mathrm{~nm})$ \\
\hline
\end{tabular}

Fonte: Os Autores (2019)

O experimento foi realizado em campo, durante a primavera, nas primeiras horas do dia, em dias de céu aberto e vento fraco, com iluminação natural e temperatura do ar de aproximadamente $23^{\circ} \mathrm{C}$. Além disso, o equipamento foi envolvido por um tecido de proteção escuro, para evitar a infiltração de luz.

O cálculo da refletância solar seguiu a metodologia apresentada por Muniz-Gäll, et.al (2018, p.507), considerando os valores do espectro padrão da ASTM (2003).

\subsection{Estimativa do albedo no estado envelhecido através de equacionamento}

Segundo Ferreira e Prado (2003) a exposição às intempéries faz com que as superfícies tenham uma alteração no albedo em função do tempo. Bretz, Akibari (1997) apud Ferreira e Prado (2003) mencionam ainda que os efeitos do envelhecimento em um contexto de cobertura, provocam uma perda na refletância de aproximadamente $15 \%$ no primeiro ano de utilização.

Sendo assim, nesta etapa será calculada a estimativa da refletância no estado envelhecido das três colorações de pavimento através da Equação (1), proposta por Levinson et.al. (2005):

$\rho$ envelhecido $=\rho 0+c(\rho$ inicial $-\rho 0)$

Sendo, $\rho 0=0,20 ; c=0,70$. $O$ cálculo do envelhecimento da refletância é modelado considerando uma redução de $30 \%$ da refletância e um decréscimo de 0,2 na refletância inicial. Santamouris e Kolokotsa (2016) relatam que uma série de pesquisas experimentais foram desenvolvidas na estimativa do envelhecimento, e que a equação proposta por Levinson et.al. (2005) apresenta valores na mesma ordem de grandeza.

\section{ANÁLISE DE RESULTADOS}

A análise de resultados se inicia com a comparação das refletâncias espectrais de cada cor de pavimento no estado novo e envelhecido. Em seguida, são calculadas a refletância solar ou albedo, através do método proposto por Pereira et al. (2015), embasado na ASTM (2016). Por fim, serão comparados os valores mensurados e calculados de albedo no estado novo e envelhecido.

\subsection{Refletância Espectral}

A refletância espectral de cada amostra de pavimento no estado novo está apresentada na Figura 3. 
Figura 3 - Refletância espectral das amostras novas.

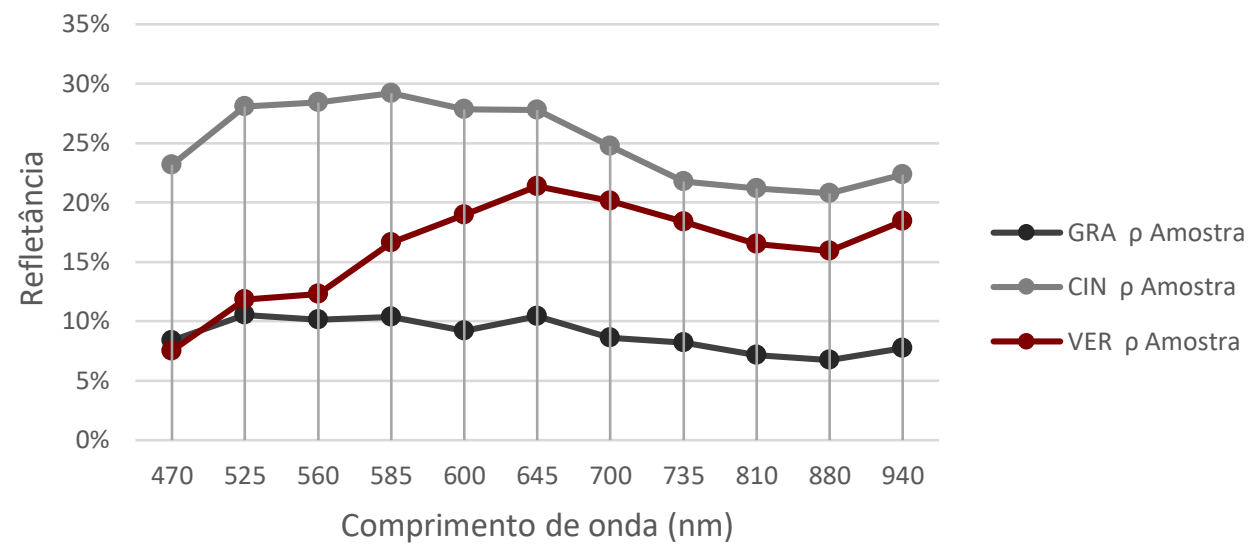

Fonte: Autor (2019)

Percebe-se que o pavimento novo na coloração cinza possui maior refletância em todo o espectro. Entretanto, na faixa do visível, no comprimento de onda $470 \mathrm{~nm}$ e $525 \mathrm{~nm}$, o pavimento grafite e o vermelho apresentam uma refletância semelhante.

A refletância espectral de cada amostra de pavimento no estado envelhecido está apresentada na Figura 4.

Figura 4 - Refletância espectral das amostras envelhecidas.

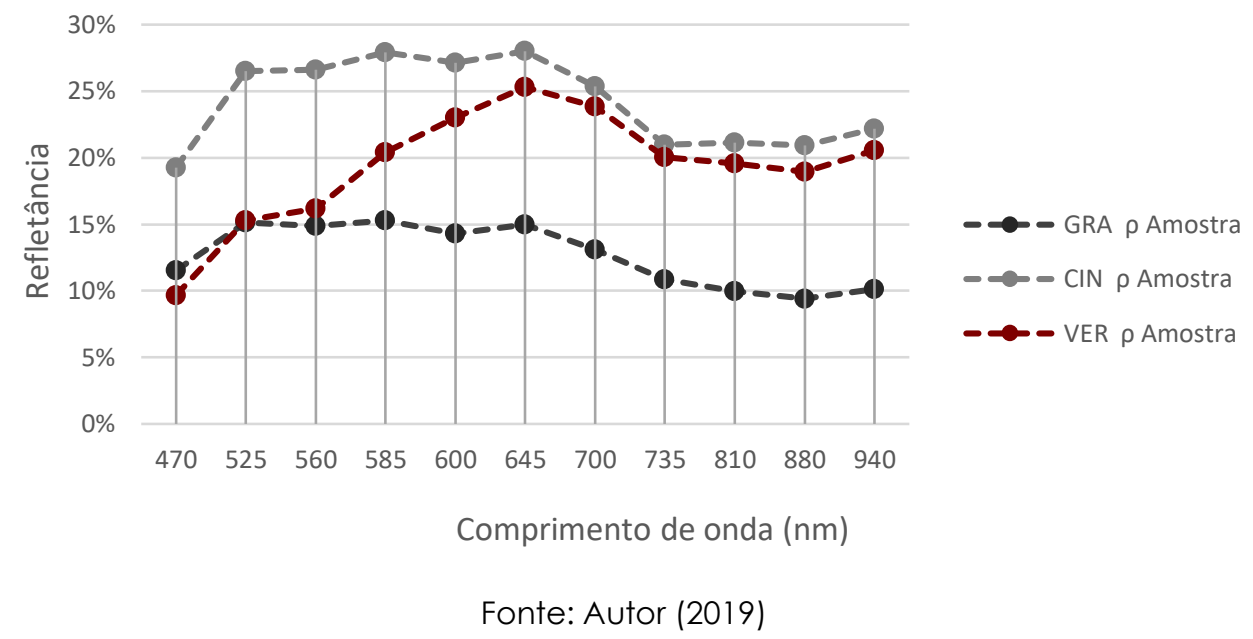

No estado envelhecido, o pavimento cinza também possui maior refletância espectral. Entretanto, na faixa do infravermelho, com comprimento de onda superior a $735 \mathrm{~nm}$, ele se assemelha à refletância do pavimento vermelho.

\subsection{Refletância solar}

A refletância solar ou albedo das amostras mensuradas e os valores de refletância considerando o envelhecido, matematicamente estão apresentadas na Tabela 1. 
Tabela 1 - Refletância do pavimento no estado novo e envelhecido, mensurado (M) e calculado (C).

\begin{tabular}{lccc}
\hline Pavimento & $\rho$ [Novo. M.] & $\rho$ [Velho. M.] & $\rho$ [Velho. C.] \\
\hline Cinza & 0,2485 & 0,2465 & 0,2340 \\
Vermelho & 0,1641 & 0,1960 & 0,1749 \\
Grafite & 0,0884 & 0,1265 & 0,1219 \\
\hline
\end{tabular}

Fonte: Os Autores

Quando comparada as três colorações, o pavimento cinza apresenta uma diminuição da refletância em relação à amostra nova. Uma hipótese, assim como proposto por Alves e Vecchia (2012), é que devido ao acúmulo de poeira, o pavimento adquiriu uma coloração mais escura, o que provocou consequentemente uma diminuição da refletância.

Em contrapartida, o pavimento grafite e vermelho apresentam um aumento do albedo com o envelhecimento, tanto nos valores mensurados, quanto calculados. A explicação está pautada possivelmente pela perda da pigmentação e pela perda de tonalidade causada pela abrasão e intempérie.

Figura 5 - Diferença do albedo superficial entre o estado envelhecido (V) e o estado novo (N).

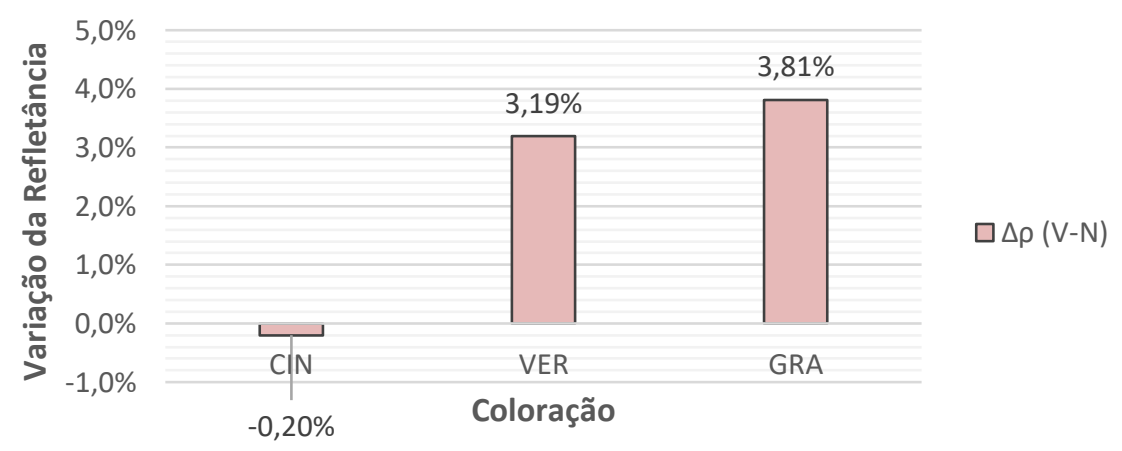

Fonte: Autor (2019)

A Figura 5 apresenta a diferença do albedo do pavimento entre o estado envelhecido e novo para cada coloração. A variação média identificada é de $3 \%$ de aumento da refletância após o envelhecimento das amostras com material escuro. A redução do pavimento cinza não foi expressiva, pois o local dos experimentos tinha boa manutenção e baixa circulação de veículos, o que não provocaria danos na coloração pelo acúmulo de sedimentos e abrasão.

\subsection{Albedo no estado envelhecido}

O albedo no estado envelhecido foi obtido inicialmente através da mensuração da refletância em um pavimento com idade de aproximadamente dois anos. Em seguida, foram aplicados os albedos do concreto novo no equacionamento proposto por Bretz, Akibari (1997). A Figura 6 apresenta a diferença da estimativa do albedo entre os dois métodos, calculado (C.) e mensurado (M.). 
Figura 6 - Variação do albedo no estado envelhecido $(\Delta \rho)$.

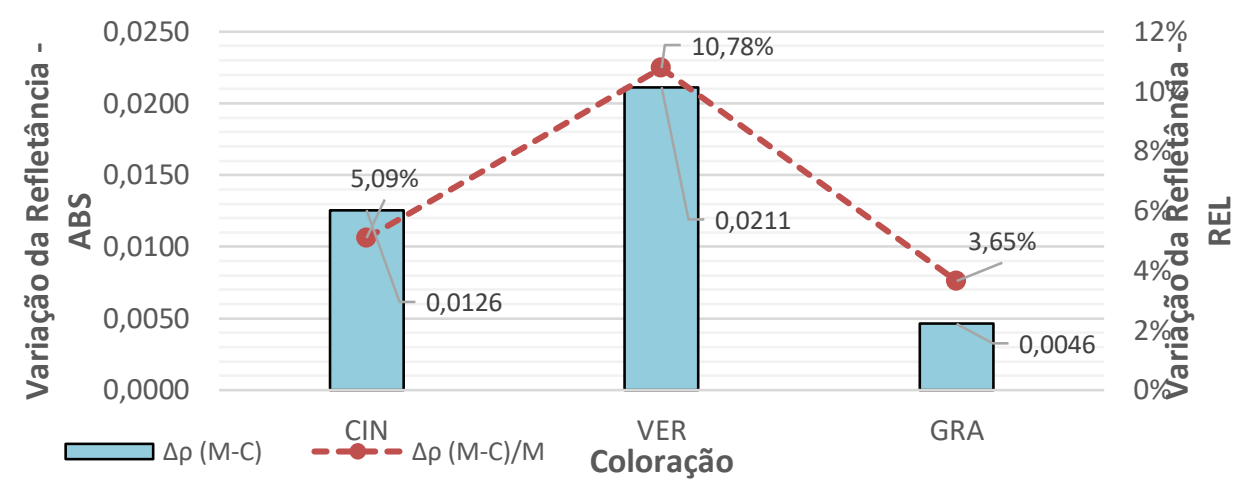

Fonte: Autor (2019)

A máxima variação identificada entre os dois métodos ocorreu com a amostra vermelha, a qual apresentou uma diferença de aproximadamente 0,02 em relação ao albedo da amostra mensurada. Na amostra grafite, essa variação foi de 0,0046 ou 3,65\%. Sendo assim, a variação não demonstra ser significativa, pois os valores de refletância são comumente expressos com um ou dois algarismos decimais, como apresentado em Santamouris e Kolokotsa (2016), Li (2016) e demais autores.

Ferreira e Prado (2003, p.7) mencionam que "a exposição ao tempo tende a diminuir a refletância dos materiais claros e aumentar a refletância dos materiais escuros", o que foi constatado nesta pesquisa. Visto os resultados apresentados, percebe-se que o pavimento cinza sofre uma diminuição do seu albedo quando envelhecido, o que pode comprometer a eficiência na mitigação das ICU ao utilizá-lo em locais com tráfego intenso e exposição à poeira.

Em contrapartida, o pavimento grafite apresenta a maior variação da refletância em relação às demais superfícies ao considerar o estado novo e envelhecido. Na presença de tráfego intenso de veículos, uma hipótese seria que o pavimento grafite perderia ainda mais sua pigmentação, o que favoreceria seu albedo na mitigação das ICU. Entretanto, há a necessidade de uma ampliação da pesquisa.

\section{CONCLUSÕES}

O pavimento corresponde a uma grande parcela da cobertura da superfície das cidades. Por isso, justifica-se entender os mecanismos de resfriamento dos pavimentos e buscar um refinamento das variáveis, considerando o contexto de envelhecimento da infraestrutura viária.

Assim, este trabalho propôs analisar o efeito do envelhecimento no albedo de três pavimentos pigmentados, através da análise da refletância mensurada pelo espectrômetro portátil e estimada por equacionamento.

Os resultados demonstram que há uma diminuição na refletância dos materiais claros e um aumento de aproximadamente $3 \%$ do albedo nos pavimentos mais escuros, relacionado ao tempo de uso, tráfego de pessoas, veículos e exposição às intempéries. Além disso, essa alteração na coloração original do pavimento frio e consequentemente a alteração do albedo pode causar uma perda do potencial de mitigação das ICU.

Por fim, percebe-se que para a análise do efeito do envelhecimento, as diferenças entre os valores instrumentados pelo espectrômetro portátil e os valores calculados através do equacionamento não são substanciais na predição do albedo de pavimentos envelhecidos. Portanto, a equação proposta neste cenário, poderia ser utilizada como forma de acompanhamento e controle da eficiência na perda potencial de albedo em função do envelhecimento de pavimentos urbanos. 


\section{AGRADECIMENTOS}

Agradecemos à CAPES, à TATU pré-moldados e ao UNASP pelo apoio no desenvolvimento desta pesquisa.

\section{REFERÊNCIAS}

ALVES, E. D. L.; VECCHIA, F. A. S. Influência de diferentes superfícies na temperatura e no fluxo de energia: um ensaio experimental. Ambiência Guarapuava (PR). v.8 n.1 p. $101-111$ Jan./Abr. 2012.

ASTM AMERICAN SOCIETY FOR TESTING AND MATERIALS. G173-03: Standard tables for reference solar spectral irradiances - direct normal and hemispherical on $37^{\circ}$ tilted surface. Philadelphia, 2003.

C1549-16: Standard test method for determination of solar reflectance near ambient temperature using a portable solar reflectometer. Philadelphia, 2016.

BRETZ, S.; AKIBARI, H.; ROSENFELD, A. Practical issues for using solar-reflective materials to mitigate urban heat islands. Atmospheric Environment, v.32, n.1, p.95-101, 1998.

ERELL, E.; PEARLMUTTER, D.; WILLIAMSON, T. Urban microclimate: Designing the spaces between Buildings. London: Earthscan, 2011.

FERREIRA, F. L., PRADO, R. T. A. Medição do albedo e análise da sua influência na temperatura superficial dos materiais utilizados em coberturas de edifícios no Brasil. Boletim Técnico da Escola Politécnica da Universidade de São Paulo 351 - Serie BT-PCC. São Paulo, 2003.

LI, H. Pavement materials for heat island mitigation: design and management strategies. 1. ed. Oxford: Elsevier, 2016.

LEVINSON, R.; AKBARI, H.; KONOPACKI, S.; BRETZ, S. Inclusion of cool roofs in nonresidential Title 24 prescriptive requirements. Energy Policy, 33, p.151-170, 2005.

MUNIZ-GÄAL, L. P.; PEZZUTO, C. C.; CARVALHO, M. F. H. de; MOTA, L. T. M. Eficiência térmica de materiais de cobertura. Ambiente Construído, Porto Alegre, v. 18, n. 1, p. 503-518, jan./mar. 2018.

PEREIRA, C. D.; MARINOSKI, D. L.; LAMBERTS, R.; et al. Guia de medição e cálculo para refletância e absortância solar em superfícies opacas (v.1). Florianópolis: UFSC, 2015.

SANTAMOURIS, M.; KOLOKOTSA, D (org.) Urban climate mitigation techniques. New York: Routledge, 2016. 